\title{
Influência da Idade de Abate e da Castração nas Qualidades Físico-Químicas, Sensoriais e Aromáticas da Carne Caprina ${ }^{1}$
}

\author{
Marta Suely Madruga², Narendra Narain², Silvana Gonçalves Brito de Arruda2, \\ Janete Gouveia Souza ${ }^{2}$, Roberto Germano Costa ${ }^{3}$, Frederico José Beserra ${ }^{4}$
}

RESUMO - Grupos de caprinos mestiços castrados e inteiros foram abatidos com idades de 175, 220, 265 e 310 dias. Os efeitos da castração e idade de abate nas qualidades físico-químicas, sensoriais e aromáticos da carne caprina foi pesquisado. O efeito castração foi observado apenas para o conteúdo de cálcio, no entanto a idade de abate apresentou um efeito significativo nos teores de umidade, proteína, cálcio, ferro e pH. Os fatores idade de abate e castração não apresentaram efeito significativo nos percentuais de fosfolipídeos porém, a idade de abate afetou os percentuais de colesterol. Caprinos castrados apresentaram maior percentual de ácidos graxos insaturados e, conseqüentemente, maior relação PUFA/SFA. Os ácidos graxos foram afetados significativamente pela castração. Não foram observadas variações nos percentuais dos ácidos graxos saturados e insaturados da carne caprina de animais abatidos com diferentes idades. O fator idade de abate apresentou maior efeito nos atributos sensoriais analisados do que o fator castração. Nos extratos da carne caprina foram identificados um total de cento e oito voláteis, sendo estes: 41 hidrocarbonetos alifáticos, 12 hidrocarbonetos alicíclicos, 19 aldeídos, 9 compostos benzênicos, 9 álcoois, 7 cetonas, 4 compostos sulfurados, 2 terpenoídes, 2 ésteres e 3 outros compostos. Os extratos da carne de caprinos castrados continham maior número de compostos voláteis do que os extratos de animais inteiros. O fator idade de abate foi o parâmetro que mais afetou as características físico-químicas e sensoriais da carne caprina. O fator castração afetou diretamente a produção de voláteis.

Palavras-chave: carne caprina, castração, físico-química, idade de abate, sensorial, voláteis

\section{Castration and Slaughter Age Effects on Physical-Chemical, Sensorial and Aromatic Quality of Goat Meat}

\begin{abstract}
Groups of crossbred castrated and intact goats were slaughtered at 175, 220, 265 and 310 days of age. The effect of castration and slaughter age on physical-chemical, sensorial and aromatic properties was researched. Calcium content was influenced by castration; however, slaughter age had a significant effect on moisture, protein, iron, calcium and $\mathrm{pH}$. Castration and slaughter age had no significant effect on phospholipids contents, but slaughter age affected the percentage of total cholesterol. Fatty acids were significantly affected by castration. Castrated goat meat contained highest unsaturated fatty acids percentage and, consequently, highest ration PUFA/SFA. There were no differences in levels of saturated and unsaturated fatty acids among the animals slaughtered at different ages. Slaughter age had a higher effect on organoleptic qualities of goat meat compared to castration. A total of 108 volatiles were presented in the extract of goat meat, they were identified as: 41 aliphatic hydrocarbons, 12 alicyclic hydrocarbons, 19 aldehydes, 9 benzenoids, 9 alcohols, 7 ketones, 4 sulphur compounds, 2 terpenoids, 2 esters and 3 other compounds. Highest numbers of volatile compounds were identified from castrated goats than from entires. Slaughter age affected more intensively the physic-chemical and sensorial characteristics of goat meat. Castration affected directly the volatile formation.
\end{abstract}

Key Words: castration, goat meat, physical-chemical, sensorial, slaughter age, volatiles

\section{Introdução}

A carne caprina tem grande potencial de consumo em razão de seu valor nutritivo e de sua aceitabilidade. Trabalhos vêm sendo realizados envolvendo estudos dos fatores que afetam a produção e os atributos físico-químicos e sensoriais da carne caprina. A raça, idade e sexo foram listados como fatores genéticos importantes que influenciam as qualidades físico-químicas e sensoriais da carne caprina. O efeito da castração não está muito claro, uma vez que a mesma pode afetar tanto o crescimento do animal quanto a composição físico-química. Figueiredo (1989) recomenda que os caprinos ma-

\footnotetext{
${ }^{1}$ Projeto financiado pelo CNPq

2 Professores Departamento de Tecnologia Química e de Alimentos (DTQA/CT/UFPB). Campus I. João Pessoa, Paraíba. Brasil. 58059900. E.mail: msmadruga@uol.com.br; narain@ct.ufpb.br

${ }^{3}$ Professor do Departamento de Agropecuária (DA/CTF/UFPB). E.mail: rgermano@cft.ufpb.br

${ }^{4}$ Professor do Departamento de Tecnologia de Alimentos (DTA/CCA/UFC). E.mail: beserra@ct.ufpb.br
} 
chos devem ser preferencialmente castrados, visando carcaças maiores e mais pesadas. Pesquisas também têm evidenciado que o abate de animais com idade mais avançada podem favorecer o rendimento das carcaças, sem que se comprometa a qualidade da carne.

Uma vez que no Nordeste brasileiro, o abate de caprinos ocorre principalmente quando estes estão com idade de 8 a 12 semanas (Madruga, 1999), resultando em um baixo rendimento de carcaça e que muito pouco se conhece sobre as influências dos fatores castração e idade de abate na qualidade físico-química da carne caprina nordestina, realizou-se nos últimos quatro anos estudos sobre a influência destes parâmetros nas características físico-químicas, sensoriais e aromáticas da carne caprina de animais machos de cruzas das raças Crioulo X Anglo Nubiano ou Saanen ou British Alpina do rebanho paraibano.

\section{Material e Métodos}

Dezesseis caprinos foram divididos inicialmente em dois grupos de oito animais cada um. Os animais de um dos grupos foram castrados, através da remoção dos testículos, ao completarem 105 dias de idade. Todos foram mantidos em regime de confinamento, alimentados com capim-elefante e ração, observando-se controle de idade e peso. Os animais foram criados no Campus VII da UFPB (Bananeiras).

Posteriormente, os caprinos foram novamente divididos em quatro grupo de quatro animais, sendo que dois eram castrados e dois inteiros. Foram, então, realizados quatro abates consecutivos, observando-se intervalos de 45 dias, os quais corresponderam às idades de 175, 220, 265 e 310 dias.

Os animais a serem abatidos, pelo método de atordoamento por concussão cerebral com marreta, foram deixados em dieta hídrica por 24 horas e pesados antes do abate. Após o abate procedeu-se à sangria, esfola e evisceração, mantendo-se as carcaças pesadas à temperatura ambiente por 6-8 horas, antes do armazenamento em câmara frigorífica a $2^{\circ} \mathrm{C}$ por 24 horas. Em seguida, procedeu-se à desossa e separação da carne, que foi embalada em sacos de polietileno sob vácuo e armazenada em freezer a $20^{\circ} \mathrm{C}$ até que os estudos fossem realizados.

Aproximadamente $500 \mathrm{~g}$ de carne a serem utilizadas nas análises físico-químicas, sensoriais e aromáticas (triplicata) foram descongelados durante uma noite, em geladeira, e trituradas em um multiprocessador, procedendo-se então à subamostragem para as diferentes análises. Todas as análises da carne caprinas foram realizadas no laboratório de Análise de Alimentos do Departamento de Tecnologia Química e de Alimentos da UFPB, Campus I.

As análises físico-químicas constaram de determinações de composição centesimal, de alguns minerais e de componentes lipídicos. Os teores de umidade, cinzas, gordura, proteínas e cálcio foram verificados segundo metodologia da AOAC (1984); as dosagens de fósforo total e ferro total segundo Egan et al. (1981). A determinação da atividade de água realizou-se em aparelho AquaLab CX2 e o pH em pHmetro Digimed PS3. As dosagens dos componentes lipídicos constaram de determinação de gordura total (Folch et al., 1957), colesterol total (Bohac et al., 1988), fosfolipídeos totais (Egan et al. 1981) e ácidos graxos (Hartman \& Lago, 1973). Detalhes da metodologia encontram-se descritos em Madruga et al. (2001) e Souza (1999).

A análise sensorial foi realizada utilizando-se o teste da Escala Hedônica (Arruda, 1999 e Madruga et al. (2000a, b) e 1999b). As análises instrumentais dos voláteis consistiu inicialmente da extração dos voláteis totais pela técnica de Likens-Nickerson (1964), seguido de identificação em CG-EM, de acordo com descrição de Madruga et al. ( 2000 a, c).

Os dados obtidos foram analisados estatisticamente através da técnica paramétrica de análise de variância (ANOVA) do programa estatístico SPSS (Statistics Package for the Social Sciences), versão 6.0.1 (Stell \& Torrie, 1980).

\section{Resultados e Discussão}

Os resultados físico-químicos da carne caprina de animais castrados e não-castrados estão apresentados na Tabela 1. O efeito castração foi observado apenas para o conteúdo de cálcio. Observou-se ainda uma interação dos fatores castração e idade de abate $(\mathrm{P}<0,01)$ para o teor de ferro, sem que esta interação tenha influenciado os percentuais de umidade, proteína, cálcio e $\mathrm{pH}$, quando se considerou todos os animais.

Os animais castrados apresentaram 33\% mais cálcio. Na literatura consultada, nenhuma informação foi encontrada que justificasse o fato observado. Considerando-se que a castração afeta diretamente o metabolismo hormonal e o crescimento do animal, 
Tabela 1 - Resultados físico-químicos e sensoriais da carne caprina de animais castrados e não-castrados

Table 1 - Physical-chemical and sensorial results of goat meat from castrated and entire animals

\begin{tabular}{|c|c|c|}
\hline $\begin{array}{l}\text { Características } \\
\text { Attribute } \\
\end{array}$ & $\begin{array}{c}\text { Castrados } \\
\text { Castrate }\end{array}$ & $\begin{array}{c}\text { Inteiros } \\
\text { Entire }\end{array}$ \\
\hline \multicolumn{3}{|l|}{ Físico-químicas } \\
\hline \multicolumn{3}{|l|}{ Physical-chemical } \\
\hline Umidade (g/100 g) & $76,09 \pm 2,86$ & $76,70 \pm 1,88$ \\
\hline \multicolumn{3}{|l|}{ Moisture } \\
\hline Cinzas $(\mathrm{g} / 100 \mathrm{~g})(A s h)$ & $0,95 \pm 0,16$ & $0,92 \pm 0,11$ \\
\hline Gordura $(\mathrm{g} / 100 \mathrm{~g})($ Fat $)$ & $3,18 \pm 1,19$ & $2,51 \pm 1,25$ \\
\hline Proteína (g/100 g) (Protein) & $20,40 \pm 2,12$ & $21,08 \pm 2,03$ \\
\hline Cálcio (mg/100 g) (Calcium) & $5,15 \pm 1,87 b$ & $3,87 \pm 1,47 \mathrm{a}$ \\
\hline Ferro (mg/100 g) (Iron) & $2,59 \pm 0,99$ & $2,35 \pm 0,97$ \\
\hline Fósforo (mg/100 g) (Phosphorus) & $175,78 \pm 20,09$ & $175,51 \pm 23,44$ \\
\hline Colesterol (mg/100 g) (Cholesterol) & $62,53 \pm 9,77$ & $57,99 \pm 11,92$ \\
\hline Fosfolipídeos (mg/100 g) (Phospholipids) & $11,09 \pm 2,65$ & $10,61 \pm 2,59$ \\
\hline Ácidos graxos saturados (Saturated fatty acids) & $46,61 \pm 1,15 \mathrm{a}$ & $48,79 \pm 1,39 b$ \\
\hline Ácidos graxos monoinsaturados (Unsaturated fatty acids) & $53,62 \pm 1,07 b$ & $49,19 \pm 1,78 \mathrm{a}$ \\
\hline Ácidos graxos polinsaturados (Polyunsaturated fatty acids) & $5,42 \pm 0,74 b$ & $4,80 \pm 0,47 a$ \\
\hline $\mathrm{pH}(\mathrm{pH})$ & $6,33 \pm 0,49$ & $6,17 \pm 0,31$ \\
\hline Atividade de água (Aa) (Water activity - $A w$ ) & $0,997 \pm 0,0011$ & $0,996 \pm 0,002$ \\
\hline \multicolumn{3}{|l|}{ Sensoriais (Sensorial) } \\
\hline Aparência (Appearance) & $6,94 \pm 1,136$ & $706 \pm 1,29$ \\
\hline Aroma caprino (Goaty aroma) & $5,43 \pm 1,81$ & $5,41 \pm 1,77$ \\
\hline Aroma de carne assada (Roasted meat aroma) & $7,20 \pm 1,11$ & $7,25 \pm 1,12$ \\
\hline Sabor (Flavour) & $7,00 \pm 1,50$ & $7,20 \pm 1,35$ \\
\hline Suculência (Juiciness) & $5,91 \pm 1,95$ & $6,13 \pm 1,86$ \\
\hline Maciez (Tenderness) & $6,26 \pm 1,88 \mathrm{a}$ & $6,56 \pm 1,77 b$ \\
\hline Textura (Texture) & $6,72 \pm 1,44$ & $6,54 \pm 1,56$ \\
\hline Qualidade total (Overall palatability) & $6,86 \pm 1,62 \mathrm{a}$ & $7,18 \pm 1,36 b$ \\
\hline
\end{tabular}

${ }_{1}^{1}$ Médias seguidas por letras diferentes nas linhas, diferem entre si pelo teste de Tukey $(P<0,05)$.

${ }^{1}$ Means with different letters within the same line differ among them by Tukey test $(P<.05)$.

é oportuno que se busque entender melhor o efeito da castração nos processos metabólicos, em especial no metabolismo do cálcio.

A carne caprina de animais castrados apresentou os menores teores de umidade e proteína, e as maiores concentrações de gordura, cinzas, ferro e fósforo, quando comparada com a de animais inteiros, embora o fator castração não apresentasse influência nestes parâmetros.

Os teores de umidade, cinzas, gorduras, proteína, cálcio, ferro e fósforo encontrados no presente trabalho assemelham-se aos das raças nativas brasileiras (Zapata et al., 1995; Arruda, 1999; Souza, 1999, Beserra, 2001), confirmando-se mais uma vez a característica da carne caprina como sendo a carne vermelha "magra", ou seja de baixo teor de gordura.

Kumar et al. (1983) e Johnson et al. (1995) relataram que o sexo e a castração não afetaram a umidade da carne caprina. Kansal et al. (1982), por outro lado, observaram que a carne de caprinos não- castrados continha mais água que a de castrados por diferentes métodos.

Os resultados da composição físico-química em cada grupo de caprinos abatidos com diferentes idades estão apresentados na Tabela 2. Dados da composição centesimal e de minerais, em geral mostraram que a idade de abate apresentou um efeito significativo $(\mathrm{P}<0,01)$ nos teores de umidade, proteína, cálcio, ferro e no $\mathrm{pH}$. Os teores de gordura, proteína e ferro aumentaram com a idade dos animais, enquanto que a umidade apresentou tendência inversa. Os resultados mostraram a influência da idade de abate na composição centesimal e de minerais, indicando que o abate de caprinos em idade mais avançada (310 dias), exerce efeitos favoráveis nos parâmetros físico-químicos investigados

Gonzalezetal. (1983), Gaili et al. (1985) e Kamble et al. (1989) reportaram uma redução geral nos teores de umidade de carnes caprinas com o aumento da idade ou do peso dos animais. Kirton (1970) e 
Tabela 2 - Resultados físico-químicos e sensoriais da carne caprina de animais abatidos com diferentes idades Table 2 - Physical-chemical and sensorial results of goat meat from animals at different ages

\begin{tabular}{|c|c|c|c|c|}
\hline \multirow[t]{2}{*}{$\begin{array}{l}\text { Atributos } \\
\text { Attributes }\end{array}$} & \multicolumn{4}{|c|}{$\begin{array}{l}\text { Idade ao abate } \\
\text { Slaughter age }\end{array}$} \\
\hline & $\begin{array}{l}175 \text { dias } \\
175 \text { days }\end{array}$ & $\begin{array}{l}220 \text { dias } \\
220 \text { days }\end{array}$ & $\begin{array}{l}265 \text { dias } \\
265 \text { days }\end{array}$ & $\begin{array}{l}310 \text { dias } \\
310 \text { days }\end{array}$ \\
\hline Físico-químicos & & & & \\
\hline $\begin{array}{l}\text { Physical-chemical } \\
\text { Umidade } \\
\text { Moisture }\end{array}$ & $77,95^{\mathrm{a}}$ & $75,16^{\mathrm{b}}$ & $77,43^{\mathrm{a}}$ & $75,02^{\mathrm{b}}$ \\
\hline Cinzas & 0,99 & 0,90 & 0,88 & 0,97 \\
\hline $\begin{array}{l}\text { Gordura } \\
\text { Fat }\end{array}$ & 2,06 & 3,42 & 1,80 & 4,08 \\
\hline $\begin{array}{l}\text { Proteína } \\
\text { Protein }\end{array}$ & $18,73 \mathrm{c}$ & $19,99^{\mathrm{b}}$ & $21,13^{b}$ & $23,11^{\mathrm{a}}$ \\
\hline $\begin{array}{l}\text { Colesterol } \\
\text { Cholesterol }\end{array}$ & $57,45^{\mathrm{b}}$ & $51,78^{\mathrm{b}} \mathrm{c}$ & $57,67^{b}$ & $74,13^{\mathrm{a}}$ \\
\hline $\begin{array}{l}\text { Fosfolipídeos } \\
\text { Phospholipids }\end{array}$ & 10,25 & 11,48 & 11,45 & 10,22 \\
\hline $\begin{array}{l}\text { Ácidos graxos saturados } \\
\text { Saturated fatty acids }\end{array}$ & 49,37 & 48,96 & 48,94 & 48,96 \\
\hline $\begin{array}{l}\text { Ác. graxos monoinsaturados } \\
\text { Unsaturated fatty acids }\end{array}$ & 52,07 & 51,45 & 52,24 & 52,55 \\
\hline $\begin{array}{l}\text { Ác. graxos poliinsaturados } \\
\text { Polyunsaturated fatty acids }\end{array}$ & 5,68 & 5,28 & 5,57 & 5,67 \\
\hline $\begin{array}{l}\mathrm{pH} \\
\mathrm{pH}\end{array}$ & $6,58^{a}$ & $6,11^{\mathrm{b}}$ & $6,21^{\mathrm{b}}$ & $6,10^{\mathrm{b}}$ \\
\hline $\begin{array}{l}\text { Atividade de água (Aa) } \\
\text { Water activity - } A w\end{array}$ & 0,996 & 0,997 & 0,997 & 0,996 \\
\hline $\begin{array}{l}\text { Cálcio } \\
\text { Calcium }\end{array}$ & $7,26^{\mathrm{a}}$ & $4,34^{\mathrm{b}}$ & $3,61^{b}$ & $3,77^{\mathrm{b}}$ \\
\hline $\begin{array}{l}\text { Ferro } \\
\text { Iron }\end{array}$ & $1,87^{b}$ & $2,45^{\mathrm{b}}$ & $2,00^{\mathrm{b}}$ & $3,65^{\mathrm{a}}$ \\
\hline $\begin{array}{l}\text { Fósforo } \\
\text { Phosphorus } \\
\text { Sensoriais } \\
\text { Sensorial }\end{array}$ & 183,23 & 168,78 & 170,86 & 179,70 \\
\hline $\begin{array}{l}\text { Aparência } \\
\text { Appearance }\end{array}$ & $7,27^{\mathrm{a}}$ & $6,98^{\mathrm{a}}$ & $7,18^{\mathrm{a}}$ & $6,58^{\mathrm{b}}$ \\
\hline $\begin{array}{l}\text { Aroma "Caprino" } \\
\text { Goaty aroma }\end{array}$ & $5,07^{\mathrm{b}}$ & $5,20^{\mathrm{b}}$ & $5,88^{a}$ & $5,51^{\mathrm{a} b}$ \\
\hline $\begin{array}{l}\text { Aroma de carne } a \text { ssada } \\
\text { Roasted meat aroma }\end{array}$ & $7,59^{\mathrm{a}}$ & $7,03^{b}$ & $7,29^{\mathrm{a}} \mathrm{b}$ & $7,10^{\mathrm{b}}$ \\
\hline $\begin{array}{l}\text { Sabor } \\
\text { Flavour }\end{array}$ & $7,50^{\mathrm{a}}$ & $6,93^{b}$ & $7,34^{\mathrm{a}}$ & $6,78^{\mathrm{b}}$ \\
\hline $\begin{array}{l}\text { Suculência } \\
\text { Juiciness }\end{array}$ & $6,21^{\mathrm{a}}$ & $5,91^{\mathrm{a}}$ & $5,77^{\mathrm{b}}$ & $5,37^{\mathrm{c}}$ \\
\hline $\begin{array}{l}\text { Maciez } \\
\text { Tenderness }\end{array}$ & $7,10^{\mathrm{a}}$ & $6,56^{\mathrm{b}}$ & $6,57^{\mathrm{a} b}$ & $5,65^{\mathrm{c}}$ \\
\hline $\begin{array}{l}\text { Textura } \\
\text { Texture }\end{array}$ & 6,75 & 6,48 & 6,52 & 6,78 \\
\hline $\begin{array}{l}\text { Qualidade total } \\
\text { Overall palatability }\end{array}$ & $8,12^{\mathrm{a}}$ & $6,95^{\mathrm{b}}$ & $7,14^{\mathrm{a} b}$ & $6,61^{b}$ \\
\hline
\end{tabular}

${ }^{1}$ Médias seguidas por letras diferentes nas linhas, diferem entre si pelo teste de Tukey $(P<0,05)$.

${ }^{1}$ Means with different letters within the same line differ among them by Tukey test $(P<.05)$. 
Schönfeldt et al. (1993) também citaram que a umidade em carne de caprinos foi menor em animais mais velhos.

Neste experimento foi observada uma tendência de aumento do conteúdo de gordura com a idade de abate no entanto a mesma não foi significativamente diferente. Gaili et al. (1972) e Gonzalez et al. (1983) relataram um aumento crescente do teor de gordura com a idade ou a massa muscular dos caprinos, embora Kamble et al. (1989) reportassem que o teor de gordura em caprinos "Osmanabadi" decresceu com o avanço da idade.

Um acréscimo da quantidade de proteína na carne caprina com o avanço da idade também foi observada. Kirton (1970) relatou aumento no teor protéico em caprinos mais velhos, porém Gaili et al. (1972) e Gonzalez et al. (1983) reportaram que o conteúdo de proteína apresentou decréscimo com o aumento da idade ou do peso do animal.

Dentre os três minerais pesquisados, a idade de abate influenciou significativamente as concentrações de cálcio e ferro, sendo que o teor de cálcio decresceu com a idade, enquanto o de ferro aumentou.

Os resultados dos componentes lipídicos (fosfolipídeos totais e colesterol) em geral mostraram, nas Tabelas 1 e 2, que os fatores idade de abate e castração não apresentaram um efeito significativo nos percentuais de fosfolipídeos, porém a idade de abate afetou a concentração de colesterol. Os teores de fosfolipídeos e colesterol estão compatíveis com valores reportados para raças exóticas caprinas por Prabhakan e Rao (1983); Park et al. (1991) e Johnson et al. (1995).

Mesmo não tendo sido detectada diferença significativa nas concentrações de fosfolipídeos, as carnes dos caprinos castrados tenderam a apresentar valores maiores do que as carnes dos animais inteiros. Os valores de fosfolipídeos, que variaram de 10,2 a $11,5 \mathrm{mg} / 100 \mathrm{~g}$, foram similares aos reportados por Prabhakar e Rao (1983) para carne caprina de animais exóticos $(10 \pm 2,1 \mathrm{mg} / 100 \mathrm{~g})$. Tais valores foram superiores aos verificados por Almeida (1990) para carne caprina de espécies nativas, cujas concentrações reportadas variaram de 6,2 a $8,3 \mathrm{mg} / 100 \mathrm{~g}$.

Observou-se que o teor de colesterol aumentou significativamente com a idade de abate porém, estes teores estavam dentro das faixas normalmente encontradas para as demais carnes vermelhas, a exemplo da carne bovina, suína, ovina, etc. Nenhum dado foi encontrado na literatura enfocando a variação do teor de colesterol com a idade em carne caprina, no entanto Bragagnolo (1997) reportou um decréscimo significativo no percentual de colesterol em carne suína com o avanço da idade de abate. Johnson et al. (1995) relatou que a castração não teve efeito no teor de colesterol de carne caprina cozida.

No perfil dos ácidos graxos da carne caprina pesquisada foram identificados 12 (doze) ácidos graxos, sendo 5 (cinco) ácidos graxos saturados e 7 (sete) ácidos graxos insaturados. Os ácidos graxos identificados foram: 14:0, 15:0, 16:0, 17:0, 18:0, 14:1, 15:1, 16:1, 17:1, 18:1; 18:2 e 18:3. O ácido graxo de maior área percentual foi o ácido oléico (C18:1). Estes dados estão reportados e discutidos em detalhes por Madruga et al (2001).

Analisando-se os percentuais totais dos ácidos graxos (Tabelas 1 e 2), observou-se que os dos ácidos graxos insaturados foram maiores do que os dos saturados, para ambos os grupos onde foram pesquisados os fatores castração e idade de abate. Este dado demonstrou mais uma vez a alta qualidade da carne caprina, no que se refere aos componentes lipídicos.

Os percentuais dos ácidos graxos em função do fator castração mostraram que os caprinos castrados apresentavam um maior percentual de ácidos graxos insaturados e, conseqüentemente, uma maior relação PUFA/SFA, enquanto que os caprinos inteiros tiveram maiores percentuais de ácidos graxos saturados e menor relação PUFA/SFA. Os ácidos graxos foram afetados significativamente pelo fator castração (Tabela 1).

Não foram observadas variações nos percentuais dos ácidos graxos saturados e insaturados da carne caprina de animais abatidos com diferentes idades (Tabela 2).

Os resultados da análise sensorial em relação à influência dos fatores castração e idade de abate estão apresentados, respectivamente, nas Tabelas 1 e 2. Através dos teste da análise sensorial, ficou evidente que o fator idade de abate apresentou um maior efeito nos atributos sensoriais analisados (Tabela 2) do que o fator castração (Tabela 1). Observou-se ainda uma interação dos efeito idade de abate $\mathrm{x}$ castração para os atributos sabor e aroma de carne assada. Nos animais castrados o aroma de "caprino" foi um pouco superior ao dos animais inteiros, embora não fosse detectada diferença significativa entre estes dois grupos.

Dentre os atributos analisados, a maciez e a 
qualidade total da carne caprina apresentaram pequenas diferenças estatisticamente significativas em favor dos animais não-castrados. Resultados semelhantes foram encontrados por Kansal et al. (1982), que observaram que a carne caprina de animais nãocastrados, de raças cruzadas Alpine X Beetle, obteve pontuação similar nos atributos maciez, sabor e suculência, em relação à da carne de animais castrados. Kumar et al. (1983) relataram que estes mesmos atributos obtiveram maiores pontuações para a carne de caprinos castrados com 1 mês de idade, quando comparada à de animais com 3 meses. Louca et al. (1977) citaram a presença de aroma "caprino" característico em carne de animais não-castrados e com idade de abate igual ou superior aos 7,5 meses, e ausência deste aroma em animais castrados com a mesma faixa de idade. Kirton, (1970) e Gaili et al. (1972) verificaram a ausência de aroma "caprino" em carne caprina de animais machos comercializados em feiras-livre.

A análise de variância mostrou que entre os oito atributos sensoriais testados (aparência, aroma de "caprino", aroma de carne assada, sabor, suculência, maciez, textura e qualidade total) apenas a textura não apresentou diferença significativa entre as quatro idades de abate analisadas. Observou-se também que os atributos aparência, suculência, maciez e qualidade total do produto receberam maior pontuação nos animais jovens, com subseqüente diminuição em relação ao acréscimo de idade. Por outro lado, o atributo aroma de "caprino" apresentou-se mais intenso nos animais mais velhos. Este fato apresentase bastante relevante considerando-se que nos países da América Latina, dentre estes o Brasil, os caprinos são abatidos bastante jovens (8-12 semanas), resultando em uma carne caprina de melhores qualidades organolépticas (Figueiredo, 1989; Madruga, 1999).

A redução da maciez com a idade resultou do fato de que com o avanço em idade, a textura é aumentada devido a presença das pontes cruzadas que estabilizam as moléculas de colágeno, fenômeno este citado por Hedrick et al. (1994). Vale citar que apesar do aumento no teor de gordura ("marmoreio"), que praticamente duplicou, este não afetou a maciez da carne caprina, indicando que o teor de umidade possivelmente apresentou uma maior influência na maciez da carne caprina do que a gordura. A melhor pontuação para o atributo suculência apresentada em caprinos abatidos com 175 dias resultou, provavel- mente, do alto teor de umidade da carne dos animais mais jovens (Tabela 2). Estes resultados estão de acordo com as observações apresentadas por Schönfeldt et al. (1993) e Hedrick et al. (1994) que descreveram a água retida em produtos cárneos como o principal contribuinte da sensação de suculência neste grupo de alimentos.

O decréscimo nos atributos sabor e aroma de carne assada com a idade de abate constituiu uma surpresa, uma vez que o aroma e o sabor das carnes em geral aumentam com as idades dos animais, segundo trabalhos de Herz \& Chang (1970), Madruga (1994, 1997), Mottram (1994). Por outro lado, como era esperado, o atributo aroma "caprino" apresentou tendência de aumento com a idade de abate, já que a menor pontuação foi detectada em caprinos abatidos com 175 dias.

Nos extratos da carne caprina de animais castrados e inteiros, abatidos com diferentes idades foram identificados um total de cento e oito voláteis (Tabela 3). Os hidrocarbonetos alifáticos, os aldeídos, os hidrocarbonetos alicíclicos e os álcoois foram os componentes voláteis detectados em maior número. Dos cento e oito voláteis identificados, $49,07 \%$ foram formados pelos hidrocarbonetos, os quais corresponderam a 53 compostos, sendo 41 hidrocarbonetos alifáticos e 12 hidrocarbonetos alicíclicos. Os 55 voláteis restantes foram identificados como sendo 19 aldeídos, 9 compostos benzênicos, 9 álcoois, 7 cetonas, 4 compostos sulfurados, 2 terpenoídes, 2 ésteres e 3 outros compostos.

A análise qualitativa dos voláteis mostrou que os extratos de carne de caprinos castrados continham maior número de compostos voláteis do que os extratos de animais inteiros. Nos animais castrados o número de voláteis variou de 86 a 103, enquanto que nos inteiros a variação foi de 56 a 79 compostos. A maior produção de voláteis nos extratos dos caprinos castrados provavelmente resulta do fato de que, os animais castrados apresentaram teores lipídicos (gordura total, fosfolipídeos, ácidos graxos e colesterol) superiores aos dos animais inteiros, mesmo não havendo diferença significativa, em algumas destas determinações, entre os animais inteiros e castrados. Madruga (1997) citou que existe um consenso de que muitos dos compostos voláteis da carne cozida são predominantemente compostos derivados dos lipídeos. Detalhes da influência dos fatores castração e idade de abate no perfil aromático da carne caprina estão reportados por Madruga et al. (2000 a). 
Tabela 3 - Classes de compostos voláteis identificados em extratos de carne caprina de animais inteiros e castrados abatidos com diferentes idades

Table 3 - Classes of volatile compounds identified from extracts of entire and castrated goat meat slaughtered at different ages

\begin{tabular}{|c|c|c|c|c|c|c|c|c|}
\hline \multirow[t]{2}{*}{$\begin{array}{l}\text { Classe e Nome do Composto } \\
\text { Class and name of compound }\end{array}$} & \multicolumn{2}{|c|}{$\begin{array}{l}175 \text { dias } \\
\text { days }\end{array}$} & \multicolumn{2}{|c|}{$\begin{array}{l}220 \text { dias } \\
\text { days }\end{array}$} & \multicolumn{2}{|c|}{$\begin{array}{l}265 \text { dias } \\
\text { days }\end{array}$} & \multicolumn{2}{|c|}{$\begin{array}{l}310 \text { dias } \\
\text { days }\end{array}$} \\
\hline & $\begin{array}{l}\text { Castrado } \\
\% \\
\text { Castrated }\end{array}$ & $\begin{array}{l}\text { Inteiro } \\
\% \\
\text { Entire }\end{array}$ & $\begin{array}{l}\text { Castrado } \\
\% \\
\text { Castrated }\end{array}$ & $\begin{array}{c}\text { Inteiro } \\
\% \\
\text { Entire }\end{array}$ & $\begin{array}{l}\text { Castrado } \\
\% \\
\text { Castrated }\end{array}$ & $\begin{array}{l}\text { Inteiro } \\
\% \\
\text { Entire }\end{array}$ & $\begin{array}{l}\text { Castrado } \\
\% \\
\text { Castrated }\end{array}$ & $\begin{array}{l}\text { Inteiro } \\
\% \\
\text { Entire }\end{array}$ \\
\hline Hidrocarbonetos alifáticos (41) & & & & & & & & \\
\hline $\begin{array}{l}\text { Aliphatic hydrocarbons } \\
\text { Número total presente }\end{array}$ & 33 & 26 & 38 & 27 & 36 & 25 & 38 & 31 \\
\hline $\begin{array}{l}\text { Total number present } \\
\text { Área relativa total } \\
\text { Total relative area } \\
\text { Hidrocarbonetos aliciclícos (12) }\end{array}$ & 28,79 & 40,38 & 37,28 & 41,67 & 35,74 & 44,57 & 28,29 & 31,94 \\
\hline $\begin{array}{l}\text { Número total presente } \\
\text { Total number present }\end{array}$ & 10 & 8 & 11 & 7 & 11 & 9 & 10 & 9 \\
\hline $\begin{array}{l}\text { Área relativa total } \\
\text { Total relative area } \\
\text { Terpenoides }(2)\end{array}$ & 19,09 & 4,49 & 15,4 & 2,79 & 8,38 & 12,65 & 13,01 & 7,51 \\
\hline $\begin{array}{l}\text { Terpenoids } \\
\text { Número total presente } \\
\text { Total number present }\end{array}$ & 1 & ND & 1 & ND & 1 & ND & 2 & 1 \\
\hline $\begin{array}{l}\text { Área relativa total } \\
\text { Total relative area } \\
\text { Compostos benzênicos (9) } \\
\text { Benzenoid compounds }\end{array}$ & 1,27 & ND & 0,24 & ND & 1,46 & ND & 0,35 & 0,89 \\
\hline $\begin{array}{l}\text { Número total presente } \\
\text { Total number present }\end{array}$ & 9 & 5 & 7 & 1 & 8 & 5 & 9 & 9 \\
\hline $\begin{array}{l}\text { Área relativa total } \\
\text { Total relative area } \\
\text { Aldeídos (19) } \\
\text { Aldehydes }\end{array}$ & 13,25 & 25,89 & 9,61 & 0,4 & 25,39 & 13,1 & 17,64 & 14,3 \\
\hline $\begin{array}{l}\text { Área relativa total } \\
\text { Total relative área } \\
\text { Álcoois }(9) \\
\text { Alcohols }\end{array}$ & 13,93 & 18,02 & 28,61 & 41,54 & 17,21 & 14,62 & 26,62 & 28,58 \\
\hline $\begin{array}{l}\text { Número total presente } \\
\text { Total number present }\end{array}$ & 6 & 4 & 6 & 5 & 5 & 3 & 9 & 6 \\
\hline $\begin{array}{l}\text { Área relativa total } \\
\text { Total relative área } \\
\text { Ésteres }(2) \\
\text { Esters }\end{array}$ & 12,66 & 7,67 & 1,5 & 1,88 & 4,89 & 9,08 & 2,09 & 2,27 \\
\hline $\begin{array}{l}\text { Número total presente } \\
\text { Total number present }\end{array}$ & 2 & ND & 1 & 1 & 2 & 1 & 2 & 2 \\
\hline $\begin{array}{l}\text { Área relativa total } \\
\text { Total relative área } \\
\text { Cetonas }(7) \\
\text { Ketones }\end{array}$ & 0,33 & ND & 0,09 & 0,08 & 0,34 & 0,42 & 0,27 & 0,36 \\
\hline $\begin{array}{l}\text { Número total presente } \\
\text { Total number present }\end{array}$ & 6 & 2 & 7 & 7 & 6 & 3 & 7 & 6 \\
\hline $\begin{array}{l}\text { Área relativa total } \\
\text { Total relative area } \\
\text { Compostos sulfurados (4) } \\
\text { Sulphur compounds }\end{array}$ & 3,49 & 1,25 & 3,2 & 2,64 & 3,3 & 2,29 & 5,24 & 3,03 \\
\hline Número total presente & 3 & 2 & 2 & ND & 3 & 2 & 4 & 3 \\
\hline $\begin{array}{l}\text { Área relativa total } \\
\text { Total number present } \\
\text { Outros compostos (3) }\end{array}$ & 1,76 & 0,7 & 0,76 & $\mathrm{ND}$ & 1,7 & 1,06 & 0,67 & 1,99 \\
\hline $\begin{array}{l}\text { Other compounds } \\
\text { Número total presente } \\
\text { Total number present }\end{array}$ & 3 & 2 & 3 & 2 & 3 & 2 & 3 & 3 \\
\hline $\begin{array}{l}\text { Total number present } \\
\text { Área relativa total } \\
\text { Total relative area }\end{array}$ & 4,61 & 1,57 & 3,25 & 8,94 & 1,50 & 2,19 & 5,40 & 9,1 \\
\hline
\end{tabular}




\section{Conclusões}

O fator idade de abate foi o parâmetro que mais afetou as características físico-químicas e sensoriais da carne caprina. $O$ fator castração afetou diretamente a produção de voláteis. Recomenda-se a castração dos animais, uma vez que animais castrados apresentaram percentuais de ácidos graxos insaturados mais elevados, maior relação PUFA/ SFA, associada a uma maior produção de compostos aromáticos.

Os dados obtidos não permitem precisar a influência do parâmetro idade de abate. Os caprinos abatidos com mais idade apresentaram maiores percentuais de composição centesimal, no entanto, a carne de animais jovens foi a preferida dos provadores.

\section{Agradecimento}

Ao $\mathrm{CNPq}$ e à CAPES, pelo apoio financeiro e pelas bolsas concedidas. Ao professor D.S. Mottram do Departamento de Biociência e de Alimentos da Universidade de Reading (Inglaterra), pela realização das análise de voláteis (CG/EM). Ao professores e alunos do PPGCTA, pela colaboração nas análises sensoriais.

\section{Literatura Citada}

ALMEIDA, M.M.M. Estudo da composição química das carnes e ovinos no sertão do Ceará. Fortaleza: Universidade Federal do Ceará, 1990. 78p. Dissertação (Mestrado em Tecnologia de Alimentos) - Universidade Federal do Ceará, 1990.

ASSOCIATION OF OFFICIAL ANALITICAL CHEMISTS AOAC. Official methods of analysis. 14.ed. Washington, D.C.: 1984. 1100 p.

ARRUDA, S.G.B. Influência da idade de abate e da castração na composição química, físico-química e qualidade sensorial de lingüiça caprina tipo frescal. João Pessoa, PB: Universidade Federal da Paraíba, 1999. 102p. Dissertação (Mestrado em Tecnologia de Alimentos) - Universidade Federal da Paraíba, 1999.

BESERRA, F.J.; MADRUGA, M.S.; MOURA, R.P. et al. Características químicas e físico-químicas da carne de caprinos srd com diferentes pesos de abate. Revista TecCarnes, v.3, n.2, p.1-7, 2001.

BOHAC, C.E.; RHEE, K.S.; CROSS, H.R. et al. Assessment of methodologies for colorimetric cholesterol assay of meats. Journal of Food Science, v.53, n.6, p.1642-1693, 1988.

BRAGAGNOLO, N. Fatores que influenciam o nível de colesterol, lipídios totais e composição de ácidos graxos em camarão e carne. Campinas: Universidade Estadual de Campinas, 1997. 123p. Tese (Doutorado em Ciência de Alimentos) - Universidade Estadual de Campinas, 1997.
EGAN, H.; KIRK, R.S.; SAWYER, R. Pearson's chemical analysis of foods. 8.ed. London: Churchill Livingstone, 1981. p.243-251.

FIGUEIREDO, E.A.P. Product quality and marketing. Improving meat goat production in the semi-arid tropics. Davis, Ca-USA/Sobral/CE-Brazil, 1989. p.122-136.

FOLCH, J.; LESS, M.; STANLEY, S. A simple method for the isolation and purification of total lipids from animal tissues. Journal Biological Chemistry, v.226, p.497-509, 1957.

GAILI, E.S.; ALI, A.E. Meat from Sudan desert sheep and goats: Part 2 - Composition of the muscular and fatty tissues. Meat Science, v.13, p.229-236, 1985.

GAILI, E.S.E.; GHANEM, Y.S.; MUKHTAR, M.S. Acomparative study of some carcass characteristics of Sudan Desert sheep and goat. Animal Production, v.14, p.351357, 1972.

GONZALEZ, F.A.N.; OWEN, J.E.; CERECERES, M.T.A. Studies on the Criollo goat of Northern Mexico: Part 2 Physical and chemical characteristics of the musculature. Meat Science, v.9, p.305-314, 1983.

HARTMAN, L.; LAGO, B.C. A rapid preparation of fatty acid methyl esters from lipids. Laboratory Practice, v.22, p.475-477, 1973.

HEDRICK, H.B.; ABERLE, E.D.; FORREST, J.C. et al. Principles of meat science. 3. ed. San Francisco: Kendall/ Hunt Publishing Company, 1994. p.123-132.

HERZ, K.O.; CHANG, S.S. Meat flavor. Advances in Food Research, v.18, p.1-83, 1970.

JOHNSON, D.D.; EASTRIDGE, J.S.; NEUBAUER, D.R. et al. Effect of Sex class on Nutrient content of meat from Young Goat. Journal of Animal Science, v.73, p.296-301, 1995.

KAMBLE, V.J.; BONDE, H.S.; KULKARNI, K.D. et al. Quality aspect of Osmanabadi goat meat. Journal Food Science Technology, v.26, p.99-101, 1989.

KANSAL, V.K.; MANCHANDA, S.; KRISHNAN, K.R. Effect of castration/sterilization on eating quality and nutritive value of meat in male goats. Journal Food Science Technology, v.19, p.203-207, 1982.

KIRTON, A.H. Body and carcass composition and meat quality of the New Zealand Feral goat. New Zealand Journal Agriculture Research, v.13, p.167-181, 1970.

KUMAR, R.; KUMAR, A.; SINGH, H. 1983. Effect of partial (Baiburtcjan's) method of castration on quality of meat in goat. Indian Journal Animal Research, v.17, p.45-49, 1983.

LIKENS, S. T.;NICKERSON, G. B. Detection of certain Hop oil constituents in brewing products. Proceeding American Society Brewing Chemistry, v.5, p.13-34, 1964.

LOUCA, A.; ECONOMIDES, S ; HANCOCK, J. Effects of castration on growth rate, feed conversion efficiency and carcass quality in Damascus goats. Animal Production, v.24, p.387-391, 1977.

MADRUGA, M.S. Artigo Técnico - Carne Caprina: Verdades e Mitos à luz da Ciência. Revista Nacional da Carne, v.264, n.23, p.34-40, 1999.

MADRUGA, M.S. Revisão: Formação do aroma cárneo. Boletim da Sociedade Brasileira de Ciência e Tecnologia de Alimentos, v.31, n.1, p.33-41, 1997.

MADRUGA, M.S. Studies on some factors affecting meat flavour formation. Reading, Inglaterra, 1994. 206p. Tese (PhD em Ciência de Alimentos) - Universidade de Reading, Reading, 1994.

MADRUGA, M.S.; SOUZA, J.G.; NARAIN, et al Castration and slaughter age effects on fat components of "Mestiço"

R. Bras. Zootec., v.31, n.3, p.1562-1570, 2002 (suplemento) 
goat meat. Small Ruminant Research, v.42, p.77-82, 2001.

MADRUGA, M.S.; ARRUDA, S.G.B.; NARAIN, N. et al. Castration and slaughter age effects on panel assessment and aroma compounds of the "mestiço" goat meat. Meat Science, v.56, p.117-125, 2000a.

MADRUGA, M.S.; ARRUDA, S.G.B.; ANDRADE, L.T. et al. Efeito da castração sobre parâmetros químicos, físico-químicos e sensoriais da carne caprina de animais mestiços. Ciência e Tecnologia de Alimentos, v.20, n.1, p.23-26, 2000 b.

MADRUGA, M.S.; ARRUDA, S.G.B.; SOUZA, J.G. et al. Castration and slaughter age effects on nutritive value and sensorial characteristics of the mestiço goat meat. In: INTERNATIONAL CONFERENCE ON GOATS, 7. 2000, Tours, França. Proceedings...Tours: IGA, 2000c. p.233-236.

MADRUGA, M.S.; ARRUDA, S.G.B.; NASCIMENTO, J.A. Castration and slaughter age effects on nutritive value of the "mestiço" goat meat. Meat Science, v.52, n.2, p.119-125, 1999a.

MADRUGA, M.S.; ARRUDA, S.G.B.; ARAÚJO, E.M.; et al. Efeito da idade de abate no valor nutritivo e sensorial da carne caprina de animais mestiços. Ciência e Tecnologia de Alimntos, v.19, n.374-379, 1999b.

MOTTRAM, D.S. Review in meat flavour. In: PIGGOTT, J.R.; PATTERSON, A. (Eds.) Understanding natural flavours. Glasgow: Blackie. 1994. p.140-177.

PARK, Y.W.; KOUASSI, M.A.; CHIN, K. B. Moisture, total fat and cholesterol in goat organ and muscle meat. Journal of Food Science, v.56, p.1191-1193, 1991.
PRABHAKAR, S.; RAO, N.P.L. Estimation of phospholipds content in meat tissue. Indian Journal of Animal Science, v.53, p.562-563, 1983.

SCHÖNFELDT, H.C.; NAUDÉ, R.T.; BOK, W.; et al. Cookingand Juiciness-related Quality characteristics of goat and sheep meat. Meat Science, v.34, p.381-394, 1993.

STELL, R.G.D., TORRIE, J.H. Principles and Procedures of Statistics. New York: McGraw-Hill, 1980. 481p.

SOUZA, J.G. Efeito da idade de abate e da castração nos componentes lipídicos de caprinos mestiços do Brejo Paraibano. João Pessoa, PB: Universidade Federal da Paraíba, 1999. 65p. Dissertação (Mestrado em Tecnologia de Alimentos) - Universidade Federal da Paraíba, 1999.

ZAPATA, J. F. F.; BARROS, N.N.; VASCONCELOS, N. M. S. In: INTERNATIONAL CONGRESS OF MEAT SCIENCE AND TECHNOLOGY. 41, 1995, Chicago. Proceedings .... Chicago: American Meat Science Association, p. 40-42.

Recebido em: 10/10/01 Aceito em: 11/03/02 